\title{
STUDY OF DIASTOLIC FUNCTION IN ASYMPTOMATIC HYPERTENSIVES IN TERTIARY CARE CENTRE
}

Nagabhushana $\mathrm{S}^{1}$, Amith Kumar², Ranganatha $\mathrm{M}^{3}$, Aravindh C.L ${ }^{4}$

\section{HOW TO CITE THIS ARTICLE:}

Nagabhushana S, Amith Kumar, Ranganatha M, Aravindh C.L. "Study of Diastolic Function in Asymptomatic Hypertensives in Tertiary Care Centre". Journal of Evolution of Medical and Dental Sciences 2014; Vol. 3, Issue 04, January 27; Page: 907-920, DOI: 10.14260/jemds/2014/1923

ABSTRACT: BACKGROUND: Hypertension is the most common underlying cardiovascular disease in patients with isolated diastolic heart failure. Diastolic dysfunction in under detected in most hypertensive patients. MATERIAL AND METHODS: retrospective study carried out in Medicine department, SIMS, Shimoga for one year from June 2012 to June 2013. 50 patients who are hypertensive without any abnormality were studied general and systemic examination done, $2 \mathrm{~d}$ echocardio graphy done in which transmitral flow velocity(E/A) is measured. RESULT: Most cases $(60 \%)$ were between $31-50$ yrs of age. Males constituted $58 \%$ and females $42 \%$ of the study group.

$56 \%$ of cases had normal diastolic function as defined by E/A ratio( $>1$ ), as compared to $44 \%$ who had abnormal diastolic function. More than half of the cases with abnormal diastolic function (defined by abnormal E/A ratio<1) had duration of hypertension more than 12 months. Diastolic blood pressures $<80$ and ${ }^{3} 90$ mmHg were significantly associated with abnormal E/A ratio. CONCLUSION: Diastolic function assessment was done on asymptomatic ambulatory hypertensive patients. The abnormal diastolic function as assessed by abnormal E/A ratio was seen in $44 \%$ of cases. Both decreased and increased diastolic blood pressure was negatively and positively associated with diastolic dysfunction. The current study demonstrated that the presence of LV diastolic dysfunction in hypertensive patients is actually greater than previously reported by studies that analyzed transmitral flow velocity curves.

KEYWORDS: Hypertension, Diastolic dysfunction, Echocardiography, E/A ration, Transmitral flow velocity.

INTRODUCTION: Hypertension is one of the most common diseases afflicting humans throughout the world. Because of the associated morbidity and mortality and the cost to society, hypertension is an important public health challenge. Over the past several decades, extensive research, widespread patient education, and a concerted effort on the part of health care professionals have led to decreased mortality and morbidity rates from the multiple organ damage arising from years of untreated hypertension. Hypertension is the most important modifiable risk factor for coronary heart disease, stroke, congestive heart failure, end-stage renal disease, and peripheral vascular disease.

Several clinical studies have reported that $30 \%$ to $50 \%$ of patients with congestive heart failure have preserved left ventricular systolic function and isolated diastolic dysfunction, i.e. isolated diastolic heart failure ${ }^{1-3}$. Preliminary data from Framingham study indicate that hypertension is the most common underlying cardiovascular disease in patients with isolated diastolic heart failure. Hypertension is postulated to impair diastolic function via multiple mechanisms even without impairment of systolic function ${ }^{4,5}$.

Left ventricular filling dynamics can be accurately assessed invasively in the cardiac catheterization laboratory using manometer-tipped catheters placed in the left ventricle with direct 
measurement of filling pressures. However, due to the invasive nature, high cost, and limited availability of laboratories, invasive approach to assess diastolic dysfunction remains impractical for widespread use. Therefore currently only noninvasive methods are being used to assess LV filling dynamics, with pulsed Doppler echocardiography, and by the pulsed Doppler transmitral flow velocity curve which has a biphasic pattern, with early diastolic wave (mitral E wave) and atrial contraction wave (mitral A wave). Hypertensive patients have impaired LV relaxation even in the absence of systolic dysfunction and many previous clinical studies have reported characteristic changes in LV filling dynamics as ${ }^{6,7}$ decreased peak mitral early diastolic filling wave (E) velocity, increased peak mitral atrial contraction wave (A) velocity, and a decreased ratio of peak mitral $\mathrm{E}$ to $\mathrm{A}$ velocities $(E \backslash A)$. This altered flow velocity curve is associated with the presence of impaired $L V$ relaxation ${ }^{8-11}$, and the decreased $\mathrm{E} \backslash \mathrm{A}$ is called an "abnormal relaxation" pattern and has been used as an indicator of diastolic dysfunction in patients with hypertension. This pattern has been described in $30 \%$ to $50 \%$ of patients with hypertension with or without preserved systolic function ${ }^{12,13}$. The current study was designed to assess prospectively diastolic dysfunction in hypertensive patients with preserved left ventricular function by transmitral flow velocity curve.

AIMS AND OBJECTIVES: To assess diastolic dysfunction in hypertensive patients with preserved left ventricular systolic function by combined transmitral flow velocity curve and pulmonary venous Doppler analysis, particularly focusing on the limitation of the transmitral flow velocity curve alone to detect diastolic dysfunction.

TREATMENT: The mainstay of pharmacologic therapy for patients with diastolic heart failure includes diuretics, nitrates, calcium channel blockers (CCBs), beta-blockers (BBs) and angiotensinconverting enzyme inhibitors (ACEI). Diuretics are useful in relieving symptoms of pulmonary congestion. Nitrates may be useful in enhancing relaxation by reducing right ventricular pressure and volume, leading to reduced pericardial restraint and improved LV filling ${ }^{14}$. As well, animal models have shown an improvement in $\mathrm{LV}$ relaxation with endogenous nitric oxide ${ }^{15}$. The negative inotropic and chronotropic properties of the CCBs make them likely to be effective in treating diastolic dysfunction. Studies have yielded conflicting results with many showing improved relaxation 16,17 , but others showing no change in the rate of relaxation ${ }^{18}$. ACEI have not been as well studied, but may hold some promise ${ }^{19}$, they may be particularly effective in the settings of hypertension with left ventricular hypertrophy and in the situation of concomitant systolic dysfunction ${ }^{20}$.

\section{Normal Range 21,22}

LVIDd

: 3.6 to $5.4 \mathrm{cms}$.

LVIDs

: 2.4 to $4.2 \mathrm{cms}$.

EF (ejection fraction) $\quad: \geq 50 \%$

DT

$\mathrm{E} / \mathrm{A}$

: $<220 \mathrm{msec}$

: $>1$

\section{MATERIALS AND METHODS:}

STUDY DESIGN: This was a retrospective study where hypertensive patients attending the outpatient department of MC Gann hospital attached to Shimoga institute of medical science, were selected randomly for enrollment into the study, after consideration of inclusion and exclusion criteria. A detailed history was taken, clinical examination and investigations performed in all cases. 
STUDY SUBJECTS: A total of 50 patients diagnosed to have hypertension with preserved systolic function (EF > 50\%) were studied from June 2012 to June 2013.

Informed consent was taken from all the study subjects.

In both cases and controls, investigations were done in the clinical biochemistry laboratory of mc gann hospital. Echocardiographic studies were performed by a noninterventional cardiologist.

INCLUSION CRITERIA: Ambulatory asymptomatic patients diagnosed to have hypertension (BP> $140 / 90 \mathrm{mmHg}$, average of two recordings taken at two separate occasions).

\section{EXCLUSION CRITERIA:}

Patients with ischemic heart disease with or without symptoms.

Patients with stroke within previous 6 months.

Patients with congestive heart failure.

Patients with atrial fibrillation.

Patients with severe hypertension BP> 200/140.

Patients with valvular heart disease.

Patients with Diabetes mellitus.

Patients with serum creatinine $>1.5 \mathrm{mg} / \mathrm{dl}$.

\section{METHODOLOGY:}

A detailed clinical history of subjects was taken.

Each subject underwent a detailed physical examination \& systemic examination.

A standard 12 lead ECG was recorded in all subjects to look for any abnormalities.

Routine hematological and biochemical investigations including, hemoglobin concentration, blood sugars, blood urea and serum creatinine were done.

Echocardiography: A qualified cardiologist performed the transthoracic echocardiographic examination on all subjects; Two-dimensional and M-mode Echocardiography was performed on Hewlett Packard SIM 7000 using 3.5 MHz transducer. Blood pressure and heart rate were measured at the time of echocardiography. Ejection fraction was calculated by measuring the internal diameter of left ventricle (LV) at the end diastole (LVIDd) \& at the end systole (LVIDs) using the Penn convention method. Two-dimensional and two-dimensional guided M-mode echocardiograms and pulsed Doppler transmitral flow velocity curves were recorded with the sample volume at the mitral tips. The averaged values of all echocardiographic parameters of at least 3 consecutive beats were used for the analysis. Doppler velocity curves were recorded at a horizontal sweep speed of $100 \mathrm{~mm} / \mathrm{s}$.

Left ventricular diastolic dysfunction was assessed by decreased E/A ratio (transmitral flow velocity curve). Normal E/A ratio was defined as $\mathrm{E} / \mathrm{A}$ ratio $\geq 1$. Abnormal $\mathrm{E} / \mathrm{A}$ ratio is defined as $\mathrm{E} / \mathrm{A}$ ratio $<1$.

STATISTICAL METHODS: Chi-square and Fisher Exact test were used to find the significance of proportions of diastolic dysfunction with various study parameters. The Student ' $t$ ' test has been used 
to find significance of mean pattern of study parameters between cases and controls. Analysis of variance has been used to find the significance of Echo parameters between the categories of diastolic dysfunction.
1. Chi-Square Test ${ }^{23,24}$
2. Fisher Exact Test ${ }^{23,24}$
3. Odds ratio $=\mathrm{ad} / \mathrm{bc}$
4. Student $t$ test ${ }^{23,} 24$
5. Analysis of Variance: F test for K Population means ${ }^{23,24}$

Statistical software: The Statistical software namely SPSS 11.0 and Systat 8.0 were used for the analysis of the data and Microsoft word and Excel have been used to generate graphs, tables etc.

\section{ANALYSIS OF RESULTS:}

Demographics: A total of 50 hypertensive patients were included in the study. The number of males was $29(58 \%)$ and that of females was 21 (42\%). The patient's age ranged from 23 to 64 years. Fifty age and sex matched healthy controls were also evaluated to obtain the normal E/A ratio values in different age groups.

\begin{tabular}{|c|c|c|}
\hline Age in years & Number & $\%$ \\
\hline$\leq 30$ & 2 & 4.0 \\
\hline $31-35$ & 10 & 20.0 \\
\hline $36-40$ & 7 & 14.0 \\
\hline $41-45$ & 8 & 16.0 \\
\hline $46-50$ & 5 & 10.0 \\
\hline $51-55$ & 6 & 12.0 \\
\hline $56-60$ & 6 & 12.0 \\
\hline $61-65$ & 6 & 12.0 \\
\hline Total & 50 & 100.0 \\
\hline
\end{tabular}

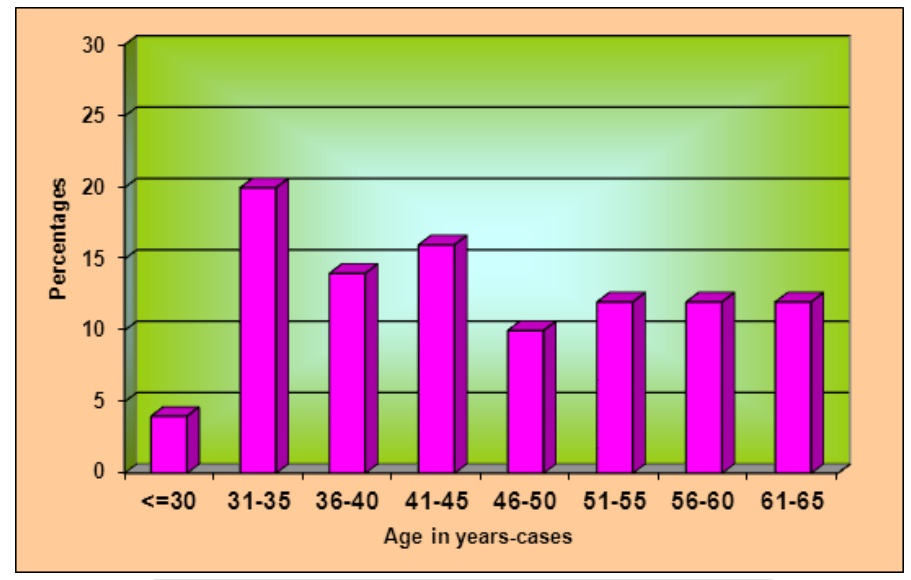

Fig. 1: Distribution age in cases 
Most cases (60\%) were between 31-50 yrs. of age (Table 1).

Males constituted $58 \%$ and females $42 \%$ of the study group.

The mean systolic blood pressure and diastolic blood pressure in cases was $156.52 \pm 18.36$ and $91.40 \pm 7.51 \mathrm{mmHg}$ respectively.

\begin{tabular}{|c|c|}
\hline Echo parameters & $\begin{array}{c}\text { Cases }(\mathrm{n}=50) \\
\text { Mean } \pm \text { SD }\end{array}$ \\
\hline EF $\%$ & $63.72 \pm 4.35$ \\
\hline LVIDS $(\mathrm{cms})$ & $2.55 \pm 0.51$ \\
\hline LVIDD $(\mathrm{cms})$ & $4.19 \pm 0.58$ \\
\hline
\end{tabular}

Table 2. Echo parameters of cases

EF: ejection fraction

LVIDS: left ventricular internal diameter systolic.

LVIDD: left ventricular internal diameter diastolic.

Ejection fraction was normal ( $>50 \%$ ) in cases (Table 2 ).

\begin{tabular}{|c|c|}
\hline E/A ratio & $\begin{array}{c}\text { Cases } \\
(\mathrm{n}=50)\end{array}$ \\
\hline Range & $0.40-2.14$ \\
\hline Mean \pm SD & $1.21 \pm 0.42$ \\
\hline
\end{tabular}

Table 3. Comparison of E/A ratio of cases

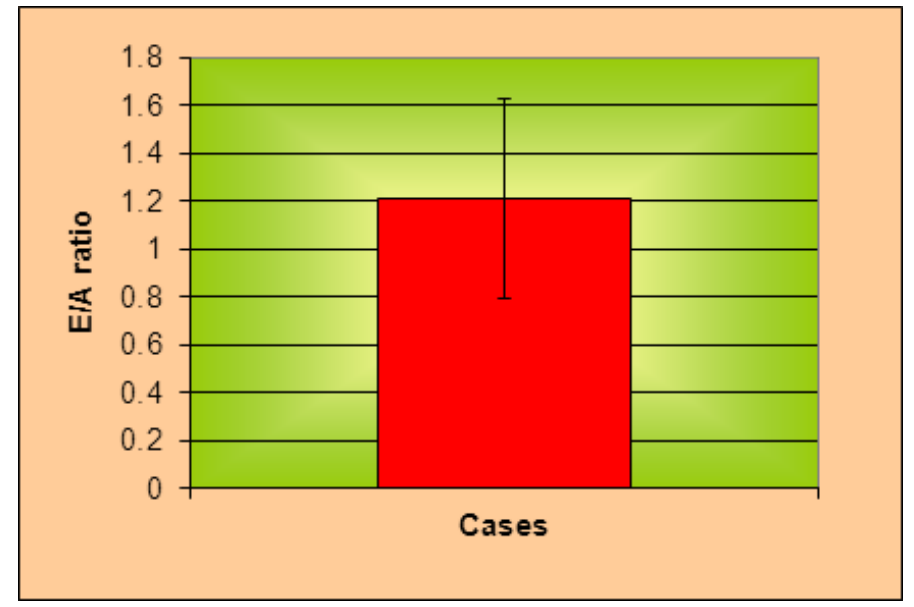

Fig. 2: Bar chart showing mean E/A ratio in cases

The E/A ratio ranged from 0.4 to 2.14 in cases with a mean of $1.21 \pm 0.42$. In E/A ratio was significantly lesser in cases, when compared to normal $(>1)(p=0.001)$ (Table 3$)$.

\begin{tabular}{|c|c|c|c|}
\hline Diastolic function defined by E/A ratio & $\begin{array}{c}\text { Number } \\
(\mathrm{n}=50)\end{array}$ & $\%$ & $\begin{array}{c}\mathrm{E} / \mathrm{A} \\
\text { Mean } \pm \mathrm{SD}\end{array}$ \\
\hline Normal E/A ratio & 28 & 56.0 & $1.52 \pm 0.21$ \\
\hline $\begin{array}{c}\text { Abnormal diastolic function } \\
\text { (E/A abnormal) }\end{array}$ & 22 & 44.0 & $0.80 \pm 0.22$ \\
\hline \multicolumn{2}{|c|}{ Table 4: Diastolic dysfunction defined by E/A ratio in cases } \\
\hline
\end{tabular}

Table 4: Diastolic dysfunction defined by E/A ratio in cases 


\section{ORIGINAL ARTICLE}

$\mathrm{E} / \mathrm{A}$ ratio normal- $\mathrm{E} / \mathrm{A}$ ratio $\geq$ age and sex adjusted mean value $-2 \mathrm{SD}$.

$\mathrm{E} / \mathrm{A}$ ratio abnormal- E/A ratio $<$ age and sex adjusted mean value $-2 \mathrm{SD}$.

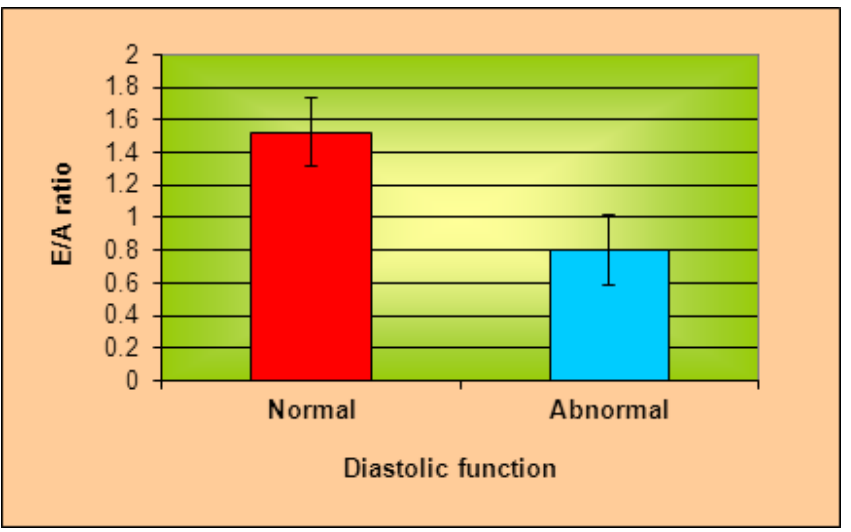

Fig. 3: E/A ratio in cases with normal and abnormal diastolic function.

$56 \%$ of cases had normal diastolic function as defined by E/A ratio, as compared to $44 \%$ who had abnormal diastolic function. (Table 4).

\begin{tabular}{|c|c|c|}
\hline \multirow{2}{*}{ Diastolic function defined by E/A ratio } & \multicolumn{2}{|c|}{ Number (\%) } \\
\cline { 2 - 3 } & Male & Female \\
\hline Normal E/A ratio (28) & $18(64 \%)$ & $10(36 \%)$ \\
\hline Abnormal E/A ratio (22) & $11(50 \%)$ & $11(50 \%)$ \\
\hline \multicolumn{2}{|c|}{ Table 5: Sex distribution of cases with } \\
diastolic dysfunction defined by E/A ratio.
\end{tabular}

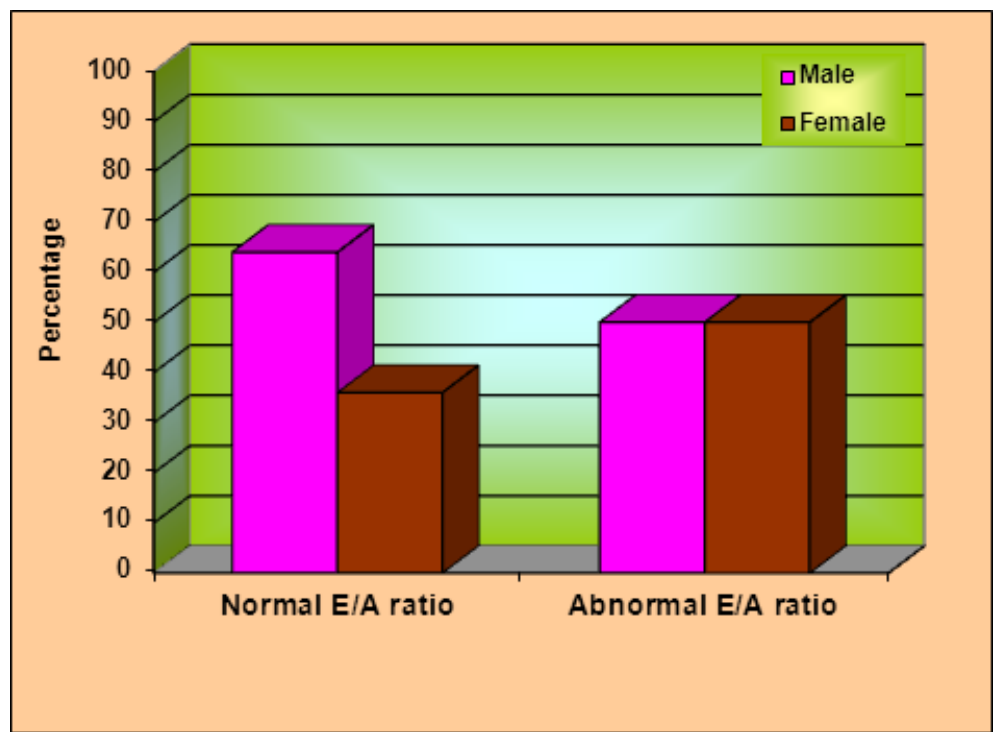

Fig. 4: Bar chart showing sex distribution of cases in normal and abnormal E/A ratio diastolic function groups. 
Majority of males had normal diastolic function (62\%). In the abnormal diastolic function group sex distribution was equal (Table 5).

\begin{tabular}{|c|c|c|}
\hline Duration of hypertension & $\begin{array}{c}\text { Normal E/A ratio group } \\
(\mathrm{n}=28)\end{array}$ & $\begin{array}{c}\text { Abnormal E/A ratio group } \\
(\mathrm{n}=22)\end{array}$ \\
\hline$\leq 6$ months & $9(32.1 \%)$ & $7(31.8 \%)$ \\
\hline $6-12$ months & $7(25.0 \%)$ & $3(13.6 \%)$ \\
\hline$>12$ months & $12(42.8 \%)$ & $12(54.5 \%)$ \\
\hline Table 6. Correlation of Diastolic function (defined by E/A ratio) \\
with duration of hypertension
\end{tabular}

More than half of the cases with abnormal diastolic function (defined by abnormal E/A ratio) had duration of hypertension more than 12 months (Table 6).

\begin{tabular}{|c|c|c|}
\hline $\begin{array}{c}\text { Systolic BP } \\
\text { in mm Hg }\end{array}$ & $\begin{array}{c}\text { Normal E/A ratio group } \\
(\mathrm{n}=28)\end{array}$ & $\begin{array}{c}\text { Abnormal E/A ratio group } \\
(\mathrm{n}=22)\end{array}$ \\
\hline$\leq 140$ & $8(28.6 \%)$ & $4(18.1 \%)$ \\
\hline $140-159$ & $9(32.1 \%)$ & $7(31.8 \%)$ \\
\hline $160-179$ & $7(25.0 \%)$ & $8(36.3 \%)$ \\
\hline$\geq 180$ & $4(14.3 \%)$ & $3(13.6 \%)$ \\
\hline \multicolumn{2}{|c|}{ Table 7. Correlation of systolic blood pressure } \\
with diastolic function (defined by E/A ratio)
\end{tabular}

The level of SBP was not significantly associated with diastolic dysfunction as defined by abnormal E/A ratio (Table 7).

\begin{tabular}{|c|c|c|c|}
\hline $\begin{array}{c}\text { Diastolic BP } \\
\text { in mm Hg }\end{array}$ & $\begin{array}{c}\text { Normal E/A ratio group } \\
(\mathrm{n}=28)\end{array}$ & $\begin{array}{c}\text { Abnormal E/A ratio group } \\
(\mathrm{n}=22)\end{array}$ & p value \\
\hline$<80$ & $11(39.3 \%)$ & $1(4.5 \%)$ & 0.004 \\
\hline $80-89$ & $2(7.1 \%)$ & $3(13.6 \%)$ & 0.447 \\
\hline$\geq 90$ & $15(53.6 \%)$ & $18(81.8 \%)$ & 0.036 \\
\hline \multicolumn{3}{|c|}{$\begin{array}{c}\text { Table 8: Correlation of diastolic blood pressure } \\
\text { with diastolic function (defined by E/A ratio) }\end{array}$} \\
\hline
\end{tabular}


ORIGINAL ARTICLE

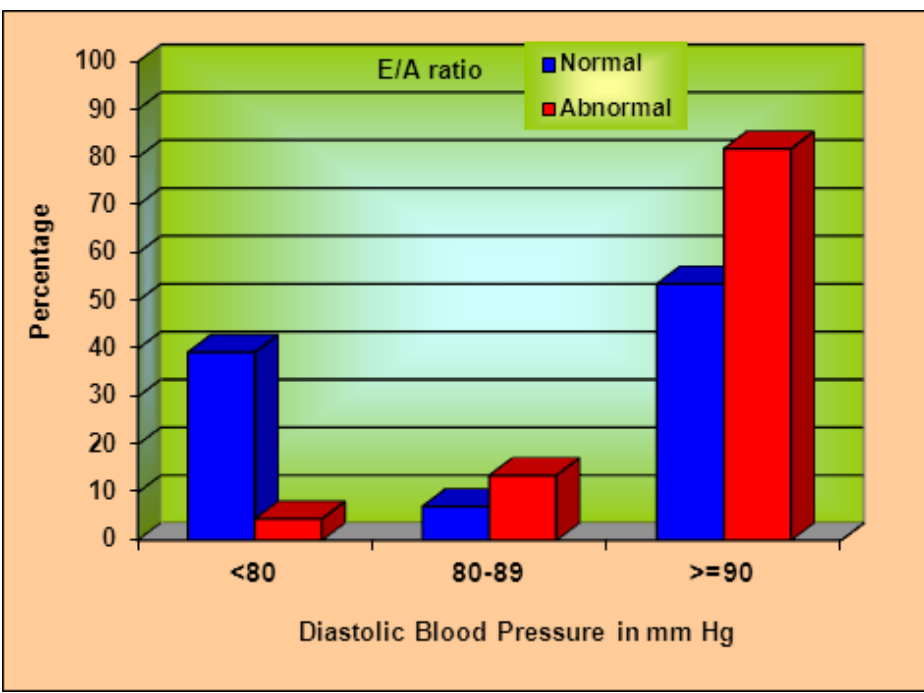

Fig. 5: Bar chart showing diastolic blood pressure in normal and abnormal E/A ratio groups

Diastolic blood pressures $<80$ and $\geq 90 \mathrm{mmHg}$ were significantly associated with abnormal E/A ratio (Table 8).

\begin{tabular}{|c|c|c|c|}
\hline \multirow{2}{*}{ Age in years } & \multicolumn{3}{|c|}{ E/A Ratio < 1 (DD) } \\
\cline { 2 - 4 } & Total no. of cases & No. of DD's & Percentage of DD's \\
\hline$\leq 30$ & 2 & 2 & $100 \%$ \\
\hline $31-35$ & 10 & 2 & $20 \%$ \\
\hline $36-40$ & 7 & 2 & $28 \%$ \\
\hline $41-45$ & 8 & 6 & $75 \%$ \\
\hline $46-50$ & 5 & 3 & $60 \%$ \\
\hline $51-55$ & 6 & 4 & $66 \%$ \\
\hline $56-60$ & 6 & 2 & $33 \%$ \\
\hline $61-65$ & 6 & 1 & $16 \%$ \\
\hline Total & 50 & 22 & $44 \%$ \\
\hline
\end{tabular}

Table 8: Diastolic dysfunction in relation to age in hypertensive patients

Incidence of Diastolic dysfunction is more above the age of 40years.

DISCUSSION: Hypertension is one of the most common diseases afflicting humans throughout the world 25,26 , and 27.

The prevalence of hypertension in Indian population is 3.80 to $15.63 \%$ in men and 2 to $15.38 \%$ in women in urban population and 1.57 to $6.93 \%$ in men and 2.38 to $8.81 \%$ in women in rural population ${ }^{28}$.

Hypertension affects various organs like central nervous system, heart, retina, kidneys and blood vessels. Hypertension affects the heart causing systolic ${ }^{29,30} \&$ diastolic dysfunction ${ }^{31}$, left 
ventricular hypertrophy ${ }^{30}$, heart failure ${ }^{32}$ and contributes to atherosclerotic vascular problems, such as coronary artery disease ${ }^{29}$.

In recent years there is an increased interest in understanding of diastolic function and its importance in common cardiovascular diseases $1,33,34-38$.

The aim of our study was to assess the diastolic function in hypertensive patients with preserved left ventricular function by transmitral flow velocity curve to detect diastolic dysfunction. This retrospective cross-sectional study was done on a relatively homogeneous and ambulatory hypertensive population.

Diastolic function is known to be influenced by several interacting factors including age, sex, duration of blood pressure, and LV hypertrophy ${ }^{39}$, all of which may potentially influence arterial compliance.

Subjects in our study underwent echocardiographic examination where diastolic function was assessed by transmitral flow velocity curves and E/A ratio [ratio of mitral early diastolic filling wave (E) velocity to mitral atrial contraction wave (A) velocity]. In our study, an E/A ratio value of 1.0 was arbitrarily chosen as the lower limit to detect impaired relaxation like in other studies ${ }^{40}$. The values for the E/A ratio observed in our impaired relaxation group (abnormal E/A ratio; $0.80 \pm 0.22$ ) were significantly lower than the normal value.

Majority of cases in our study were males (58\%). A similar male preponderance was noted in several earlier studies ${ }^{41-44}$.

The mean age of cases in our study was $45.70 \pm 11.12$ years. This was comparable to mean age of cases in the earlier Asian studies. (Masliza et al $^{45}$. mean age 43.1 $\left.\pm 5.7 y e a r s\right)$, whereas other western studies had enrolled older cases (Mottram et al ${ }^{41} .58 \pm 8$ years, Yamamato et al ${ }^{42} .69 \pm 6$ years, Mitra et $\mathrm{al}^{43}$. 54.48years, Adewole et $\mathrm{al}^{44} .59 \pm 10.4$ years). This may be due to enrollment of follow-up patients with hypertension.

Diastolic dysfunction as defined by E/A ratio was found to be abnormal in $44 \%$ of cases in our study. Mottram et $\mathrm{al}^{41}$. had found abnormal E/A ratio in $40 \%$ of their patients which is comparable to our finding. Other investigators have found a lower proportion of cases with abnormal E/A ratio in their study group. Yamamato et $\mathrm{al}^{42}$. found abnormal E/A ratio in $31 \%$ of their cases, which may be due to lower mean DBP in their cases as compared to our study (74 v/s $91 \mathrm{~mm} \mathrm{Hg}$ ). Masliza et al 45 . found abnormal E/A ratio in only $18.6 \%$ of their cases. This could be due to lesser duration of hypertension in their cases. In Masliza's ${ }^{45}$ study all subjects were newly diagnosed hypertensive (duration less than 6 months), whereas only $32 \%$ of subjects were newly diagnosed hypertensive in our study.

Although the sex ratio in abnormal E/A ratio group was equal (50\% v/s 50\%), more males tended to have normal E/A ratio (62\% v/s 48\%) in our study. Mottram et al ${ }^{41}$. had found that female sex was an independent predictor of diastolic dysfunction. In our study there was a preponderance of female sex with diastolic dysfunction (52\% females $\mathrm{v} / \mathrm{s} 38 \%$ of males).

Abnormal E/A ratio correlated with DBP $\geq 90 \mathrm{~mm} \mathrm{Hg}$ in our study. There was also correlation between normal diastolic function defined by $\mathrm{E} / \mathrm{A}$ ratio and $\mathrm{DBP}<80 \mathrm{mmHg}(\mathrm{p}=0.004)$. Mottram et al ${ }^{41}$. had also found DBP to be significantly associated with diastolic dysfunction a finding similar to our study. 
Our study did not find any association between abnormal E/A ratio and duration of hypertension and systolic blood pressure. No other study except Masliza's ${ }^{45}$ study had found an association between systolic BP, duration of hypertension and diastolic dysfunction.

Diastolic BP level $\geq 90 \mathrm{mmHg}$ was significantly associated with diastolic dysfunction. Mottram et $\mathrm{al}^{41}$. have also found, elevation in diastolic blood pressure to be significantly associated with diastolic dysfunction. Indeed the study considered the diastolic BP to be an independent risk factor for diastolic dysfunction. Diastolic blood pressure is dependent on peripheral resistance and increases afterload of the heart. Increased afterload may promote myocyte hypertrophy and may also directly slow LV relaxation and contribute to diastolic dysfunction. Our study also found correlation between $\mathrm{DBP}<80 \mathrm{mmHg}$ and normal diastolic function $(\mathrm{p}=0.001)$. This has not been shown by previous studies.

Although earlier studies had found correlation between left ventricular hypertrophy and diastolic dysfunction ${ }^{46}$, recent studies including our study have not confirmed the association. Masliza et $\mathrm{al}^{45}$. also did not find correlation between LVH and diastolic dysfunction and have suggested that a compensatory physiological mechanism in response to pressure load during early hypertension even before onset of demonstrable LVH may be the cause for diastolic dysfunction ${ }^{47,48,49}$.

In our study Diastolic dysfunction in relation to age is more in above 40years of age group; it is comparable to study done by $\mathrm{H}$. Schirmer, $\mathrm{P}$. Lunde et al ${ }^{50}$. lesser incidence in above 55years of age may be due to pseudonormalization in which E/A ratio will be abnormally high due to severe diastolic dysfunction.

Clinical implications: The current findings have potential relevance in clinical practice for evaluation of hypertensive patients as diastolic dysfunction may be an early manifestation of cardiac involvement in hypertension ${ }^{2}$. studies have shown that anti-hypertensive such as ACE inhibitors may be more useful in this condition. The presence of diastolic dysfunction also provides an additional evidence of end-organ damage ${ }^{51}$. The frequency of isolated diastolic heart failure in elderly hypertensive patients suggests that asymptomatic hypertensive patients with diastolic dysfunction may be at risk of progression to diastolic heart failure. More longitudinal studies of hypertensive patients with evidence of diastolic dysfunction are needed to determine the predictive value of these noninvasive indicators of diastolic dysfunction.

Study limitations: Our study group consisted of small homogeneous group of hypertensives. As echocardiographic examination could be performed in lesser number of patients than was desirable. Hence, the prevalence of LV diastolic dysfunction obtained in the current study may not be identical when applied to a larger or different population of hypertensives, and a future study with larger population may be required.

The study included patients who were on medications. Diastolic function may be affected by medications as has been shown in several previous studies. This may affect the prevalence of diastolic dysfunction in the current study subjects. The medications were continued by the patients in our study for ethical reasons. In the study diastolic dysfunction was calculated using transmitral flow velocity curve, which fail to detect the diastolic dysfunction in pseudonormal group, which can be detected by studying pulmonary flow velocity curve. 
CONCLUSIONS: Diastolic function assessment was done on asymptomatic ambulatory hypertensive patients. Majority were males (58\%). The abnormal diastolic function as assessed by abnormal E/A ratio was seen in $44 \%$ of cases. There was a preponderance of female sex in this abnormal diastolic function group. Diastolic blood pressure was significantly associated with diastolic dysfunction.

Both decreased and increased diastolic blood pressure was negatively and positively associated with diastolic dysfunction. The diastolic dysfunction was seen in patients with LVH, however this is statistically not significant indicating LVH is not the only cause for diastolic dysfunction in hypertensives.

The current study demonstrated that the presence of LV diastolic dysfunction in hypertensive patients is actually greater than previously reported by studies that analyzed transmitral flow velocity curves.

SUMMARY: Ambulatory hypertensives cases had abnormality in diastolic function (44\%) as assessed by transmitral Doppler signals (E/A ratio). The current study demonstrated that the presence of LV diastolic dysfunction in hypertensive patients is actually greater than previously reported by studies that analyzed transmitral flow velocity curves. To avoid overlooking patients with diastolic dysfunction analysis of transmitral flow velocity curves is recommended in all hypertensive patients irrespective of duration of hypertension.

\section{BIBLIOGRAPHY:}

1. Senni M, Tribouilloy CM, Rodeheffer RJ, et al. Congestive heart failure in the community: a study of all incident cases in Olmsted County, Minnesota, in 1991. Circulation. 1998; 98:2282-2289.

2. Vasan RS, Larson MG, Benjamin EJ, Evans JC, Reiss CK, Levy D. Congestive heart failure in subjects with normal versus reduced left ventricular ejection fraction: prevalence and mortality in a population-based cohort. J Am Coll Cardiol. 1993; 33:1948-1955.

3. Soufer R, Wohlgelernter D, Vita NA, et al. Intact systolic left ventricular function in clinical congestive heart failure. Am J Cardiol. 1985; 55:1032-1036.

4. Hirota Y. A clinical study of left ventricular relaxation. Circulation. 1980; 62:756-763.

5. Bonow RO, Udelson JE. Left ventricular diastolic dysfunction as a cause of congestive heart failure: mechanisms and management. Ann Intern Med. 1992; 117:502-510.

6. Kitabatake A, Tanouchi J, Masuyama T, et al. Limited atrial compensation to reduced early diastolic filling in hypertensive patients with advanced left ventricular hypertrophy: a Doppler Echocardiographic study. Heart vessels. 1989; 5:33-40.

7. Phillips RA, Coplan NL, Krakoff LR, et al. Doppler Echocardiographic analysis of left ventricular filling in treated hypertensive patients. J Am Coll Cardiol. 1987; 9:317-322.

8. Yamamoto K, Redfield MM, Nishimura RA. Analysis of left ventricular diastolic function. Heart. 1996; 75(suppl 2):27-35.

9. Nishimura RA, Abel MD, Hatle LK, Tajik AJ. Assessment of diastolic function of the heart: background and current applications of Doppler echocardiography, part II: clinical studies. Mayo clin proc. 1989; 64:181-204.

10. Appleton CP, Hatle LK. The natural history of left ventricular filling abnormalities: assessment by two-dimensional and Doppler echocardiography. Echocardiography. 1992; 9:437-457. 
11. Thomas JD, Choong CY, Flachskampf FA, Weyman AE. Analysis of the early transmitral Doppler velocity curves: effect of primary physiological changes and compensatory preload adjustment. J Am Coll Cardiol. 1990; 16:644-655.

12. Verdecchia P, Schillaci G, Guerrieri M, et al. Prevalence and determinants of left ventricular diastolic filling abnormalities in an unselected hypertensive population. Eur Heart J 1990; 11:679-691.

13. Fouad FM. Cardiac function and dysfunction in hypertension. Cleve Clin J Med. 1994; 61:351355.

14. Smith ER, Smiseth OA, Knigma I, et al. Mechanism of action of nitrates: role of changes in venous capacitance and in the left ventricular diastolic pressure-volume relation. Am J Med 1984; 76A:14-21.

15. Groot-Mason R, Anning P, Evans H, Lewis MJ, Shah AM. Modulation of left ventricular relaxation in isolated ejecting heart by endogenous nitric oxide. Am J Physiol 1994; 267(Heart Circ Physiol 36):H1804-H1813.

16. Bonow RO, Dilsizian V, Rosing DR, et al. Verapamil-induced improvement in left ventricular diastolic filling and increased exercise tolerance in patients with hypertrophic cardiomyopathy: short-term and long-term effects. Circulation 1985; 72(4):853-864.

17. Lorell BH, Paulus WJ, Grossman W, Wynne J, Cohn PF. Modification of abnormal left ventricular diastolic properties by nifedipine in patients with hypertrophic cardiomyopathy. Circulation 1982; 65(3):499-507.

18. Nishimura RA, Schwartz RS, Holmes DR, Tajik AJ. Failure of calcium channel blockers to improve ventricular relaxation in humans. J Am Coll Cardiol 1993; 21:182-188.

19. Haber HL, Powers ER, Gimple LW, et al. Intracoronary angiotensin converting enzyme inhibition improves diastolic function in patients with hypertensive left ventricular hypertrophy. Circulation 1994; 89:2616-2625.

20. Hayashida W, Van Eyll C, Rousseau MF, Pouleur H. Regional remodelling and non-uniform changes in diastolic function in patients with left ventricular dysfunction: modification by longterm enalapril treatment. J Am Coll Cardiol 1993; 22:1403-1410.

21. Rakowski H, Appleton C, Chan KL, et al. Canadian consensus recommendations for the measurement and reporting of diastolic dysfunction by echocardiography: from the investigators of Consensus on Diastolic Dysfunction by Echocardiography (review). J Am Soc Echocardiogr 1996; 9:736-760.

22. Normal values of Doppler echocardiographic measurements in adults (Table A-7), Appendices in Harrison's Principles of Internal Medicine, 15th ed Braunwald et al. McGraw Hill and Company 2001; Vol. 2: A-5.

23. Bernard Rosner (2000), Fundamentals of Biostatistics, $5^{\text {th }}$ Edition, Duxbury.

24. M. Venkataswamy Reddy (2002), Statistics for Mental Health Care Research, NIMHANS publication, INDIA.

25. Seventh Report of the Joint National Committee on Prevention, Detection, Evaluation, and Treatment of High Blood Pressure, Aram V. Chobanian; George L. Bakris; Henry R. Black; William C. Cushman; Lee A. Green; Joseph L. Izzo, Jr et al; the National High Blood Pressure Education Program Coordinating Committee, Hypertension. 2003; 42:1206. 
26. Burt VL, Whelton P, Roccella EJ, Brown C, Cutler JA, Higgins M, et al. Prevalence of hypertension in the US adult population. Results from the Third National Health and Nutrition Examination Survey, 1988-1991. Hypertension. 1995; 25: 305-313.X

27. Bechung, Ooi Boon Seng, Chen, B.T.M. Toh, C.C.S. and KHOO, Causes of hypertension in the young, Brit. Med.Jr., II, 744, 1970.

28. M. Paul Anand, chapter Essential hypertension. API text book of medicine, $7^{\text {th }}$ edition; 452.

29. Vasan RS, Larson MG, Leip EP, Evans JC, O’Donnell CJ, Kannel WB, et al. Impact of high-normal blood pressure on the risk of cardiovascular disease. N Engl J Med. 2001; 345: 1291-1297.

30. Cuocolo A, Sax FL, Brush JE, Maron BJ, Bacharach SC, Bonow RO. Left ventricular hypertrophy and impaired diastolic filling in essential hypertension. Diastolic mechanisms for systolic dysfunction during exercise. Circulation 1990; 87:978-986.

31. Hartford M, Wikstrand J, Wallentin I, Ljungman S, Wilhelmsen L, Berglund G. Diastolic function of the heart in untreated primary hypertension. Hypertension 1984; 6:329-338.

32. Vasan RS, Levy D. The role of hypertension in the pathogenesis of heart failure. Arch Intern Med 156:1789, 1996.

33. Vasan RS, Benjamin EJ, Levy P. Prevalence, clinical features and prognosis of diastolic heart failure: an epidemiologic perspective. J Am Coll Cardiol 1995; 26:1565-1574.

34. Zile MR, Brutsaert DL. New concepts in diastolic dysfunction and diastolic heart failure. Part I. Diagnosis, prognosis, and measurements of diastolic function. Circulation 2002; 105:1387-93.

35. Zile MR, Brutsaert DL. New concepts in diastolic dysfunction and diastolic heart failure. Part II. Causal mechanisms and treatment. Circulation 2002; 105:1503-8.

36. Vasan RS, Benjamin EJ. Diastolic heart failure: no time to relax. N Engl J Med 2001; 344:56-59.

37. Petrie M, McMurray J. Changes in notions about heart failure. Lancet 2001; 358:432-4.

38. Chen HH, Lainchbury JG, Senni M, et al. Diastolic heart failure in the community: clinical profile, natural history, therapy and impact of proposed diagnostic criteria. J Card Fail 2002; 8:279-87.

39. Kitzman DW. Why is diastolic heart failure in older patients the cardiologist's enigma? Dialogues Cardiovasc Med 2001; 6:95-103.

40. Rakowski H, Appleton CP, Chan KL, Dumesnil JG, Honos G, Jue J et al. Canadian Consensus Recommendations for the Measurement and Reporting of Diastolic Dysfunction by Echocardiography. J Am Soc Echocardiogr 1996; 9:736-760.

41. P M Mottram, B A Haluska, R Leano, S Carlier, C Case, T H Marwick. Relation of arterial stiffness to diastolic dysfunction in hypertensive heart disease. Heart 2005; 91:1551-1556.

42. Kazuhiro Yamamato, Daniel J, Wilson, Vincent J, Canzanello, Margaret M et al. left ventricular diastolic dysfunction in patients with hypertension and preserved systolic function. Mayo clin proc. 2000; 75:148-155.

43. B Mitra, SD Singh, S Basu, D Kumar, S Mondal, Ka Sema et al. A Profile of Clinical, Electrocardiographic and Echocardiographic Studies of Left Ventricular Hypertrophy in Hypertension Patients. Indian Heart J 2005; 57: 529-531.

44. Adewole A. Adebiyi, Akinyemi Aje, Okechukwu S. Ogah, Dike B et al. Left Ventricular Diastolic Function Parameters in Hypertensives. Journal of the National Medical Association, January 2005:97, no. $1 ; 41-45$. 
45. M Masliza, S Mohd Daud, Y Khalid, 2005 Young Investigator's Award Winner: Assessment of Diastolic Function in Newly Diagnosed Hypertensives. Ann Acad Med Singapore 2005; 34:684688.

46. Hoit BD, Walsh RA. Diastolic function in hypertensive heart disease. In: Gaasch WH, LeWinter M, editors. Left Ventricular Diastolic Dysfunction and Heart Failure. Philadelphia: Lea and Febiger, 1994:354 -372.

47. Lorell BH. Diastolic dysfunction in pressure overload hypertrophy and its modification by angiotensin II; current concepts. Basic Res Cardiol. 1992; 87(suppl 2):163-172.

48. Kass DA, Wolff MR, Ting CT. et al. Diastolic compliance of hypertrophied ventricle is not acutely altered by pharmacological agents influencing active processes. Ann Intern Med. 1993; 119:466-473.

49. Sobue T, Yokota M, Iwase M, Ishihara H. Influence of left ventricular hypertrophy on left ventricular function during dynamic exercise in the presence or absence of coronary artery disease. J Am Coll Cardiol. 1995; 25:91-98.

50. H. Schirmer, P. Lunde et al. Mitral flow derived Doppler indices of left ventricular diastolic function in a general population. The Tromsø study. European Heart Journal (2000) 21, 13761386.

51. Bella JN, Palmieri V, Roman MJ, Liu JE, Welty TK, Lee ET, Fabsitz RR, Howard BV, Devereux RB: Prognostic significance of abnormal peak early to late diastolic filling ratio in middle-aged to elderly adult American Indians: the Strong Heart Study (Abstract). J Am Coll Cardiol 2000; 35 (Suppl. A):293A.

\section{AUTHORS:}

1. Nagabhushana $S$.

2. Amith Kumar

3. Ranganatha M.

4. Aravindh C.L.

\section{PARTICULARS OF CONTRIBUTORS:}

1. Assistant Professor, Department of General Medicine, Shimoga Institute of Medical Sciences (SIMS), Shimoga.

2. Assistant Professor, Department of General Medicine, Shimoga Institute of Medical Sciences (SIMS), Shimoga.

3. Assistant Professor, Department of General Medicine, Shimoga Institute of Medical Sciences (SIMS), Shimoga.
4. Associate Professor, Department of General Medicine, Shimoga Institute of Medical Sciences (SIMS), Shimoga.

\section{NAME ADDRESS EMAIL ID OF THE CORRESPONDING AUTHOR:}

Dr. Nagabhushana S., Near GK School, Jenukalleshwari Krupa, Aashok Nagar $2^{\text {nd }}$ Cross, Shimoga - 577201.

E-mail: sn_bhushan@yahoo.co.in

Date of Submission: 28/12/2013.

Date of Peer Review: 29/12/2013.

Date of Acceptance: 17/01/2014.

Date of Publishing: 23/01/2014. 